\title{
The role of surgical margins in chondrosarcoma
}

\section{Stevenson, Jonathan D.}

2018-09

Stevenson, J D , Laitinen , M K , Parry , M C , Sumathi , V , Grimer , R J \& Jeys , L M 2018 ,

' The role of surgical margins in chondrosarcoma ', European Journal of Surgical Oncology , vol. 44 , no. 9 , pp. 1412-1418 . https://doi.org/10.1016/j.ejso.2018.05.033

http://hdl.handle.net/10138/305126

https://doi.org/10.1016/j.ejso.2018.05.033

publishedVersion

Downloaded from Helda, University of Helsinki institutional repository.

This is an electronic reprint of the original article.

This reprint may differ from the original in pagination and typographic detail.

Please cite the original version. 


\title{
The role of surgical margins in chondrosarcoma
}

\author{
Jonathan D. Stevenson a , Minna K. Laitinen ${ }^{\text {b. *, }}$, Michael C. Parry a , Vaiyapuri Sumathi a, \\ Robert J. Grimer ${ }^{\mathrm{a}}$, Lee M. Jeys ${ }^{\mathrm{a}}$ \\ ${ }^{\text {a }}$ Royal Orthopaedic Hospital NHS Foundation Trust, Birmingham, UK \\ ${ }^{\mathrm{b}}$ Department of Orthopaedics and Traumatology, Helsinki University Central Hospital, Helsinki, Finland
}

\section{A R T I C L E I N F O}

\section{Article history:}

Accepted 24 May 2018

Available online 8 June 2018

\section{Keywords:}

Sarcoma

Chondrosarcoma

Margins of excision

Multivariate analysis

Retrospective study

\begin{abstract}
A B S T R A C T
Introduction: Chondrosarcoma (CS) is the second most common primary bone sarcoma with no clear role for adjuvant therapy. The purpose of this study was to investigate (1) the relationship between surgical excision margins and local recurrence free survival (LRFS), and (2) the role of local recurrence (LR) in disease specific survival (DSS) in CS of the extremity and pelvis.

Material and methods: 341 pelvic and extremity CS diagnosed between 2003 and 2015 were studied retrospectively.

Results: LR developed in $23 \%$ of cases. Pelvic location, pathologic fracture, margin and grade were significant factors for LR after univariate analysis. Multivariate analysis revealed surgical margin and pelvic location as positive factors for LR, and grade- 1 and 2 CS as negative factors for LR. Pathologic fracture, central versus peripheral, grade, and LR were significant factors with univariate analysis for DSS; and grade was significant after multivariate analysis for all patients for DSS. After competing risk analysis, LR was statistically significant for DSS in grade-2 and grade-3 tumors.

Conclusion: Surgical margins determine LR in all CS grades, but LR affects DSS only in grade- 2 and grade3 tumors. Although narrow margins are acceptable in grade- 1 tumors, since biopsy is unreliable in predicting final grade, a minimum 4-mm margin should be the aim in all cases.
\end{abstract}

(1) 2018 Elsevier Ltd, BASO The Association for Cancer Surgery, and the European Society of Surgical Oncology. All rights reserved.

\section{Introduction}

Chondrosarcoma (CS) is the second most common primary bone tumor and the most common in adults [1]. CS are locally aggressive cartilage matrix forming tumors with a heterogeneous morphology and behavior. CS can be classified as central or peripheral, arising in a pre-existing osteochondroma, and demonstrate a number of histopathological variants with variable biological behavior and prognosis [2,3]. For both central CS and peripheral CS three different histological grades exist, based on cellular atypia, mitotic activity and cellularity [4]. Dedifferentiated (DD) CS is a high-grade, non-cartilaginous sarcoma within a (usually low-grade) malignant cartilage-forming tumor [5].

Low grade (grade-1) CS tumors, which grow insidiously and rarely metastasize, have a good prognosis. High grade CS and DD CS, by comparison, have a very poor prognosis due to the rapid growth

\footnotetext{
* Corresponding author. Department of Orthopaedics and Traumatology, Helsinki University Central Hospital, Topeliuksenkatu 5, 00260, Helsinki, Finland.

E-mail address: minna.laitinen@hus.fi (M.K. Laitinen).
}

of the tumor and the propensity for early metastasis. CS are relatively resistant to radiotherapy and conventional chemotherapy, rendering surgery the principle treatment $[2,6-8]$.

In grade-1 CS, the risk of local recurrence and metastasis is low, consequently marginal or intralesional surgical margins are deemed acceptable [8-11]. There is often considerable difficulty in differentiating between low grade CS and benign cartilaginous tumors, and recent changes in definition have led to an increase in the number of tumors labeled as chondrosarcoma [4].

In high grade CS, wide surgical excision offers the best prognosis for cure and local control. It has long been established that the incidence of metastasis and therefore disease specific survival is dependent upon the histological grade, and that local recurrence is determined, at least in part, by the adequacy of the surgical margin [1]. Other reported prognostic factors for disease specific survival include the development of local recurrence [7], which is attributable to an inadequate margin [6,12], and pelvic tumor location $[6,12,13]$. Risk factors for local recurrence include greater tumor size and narrow surgical margins $[7,12]$.

Controversy exists as to the effect of local recurrence (LR) on disease specific survival (DSS). Recurrence is often associated with tumor 
progression to a higher grade, which is associated with metastasis and death. Minimizing local recurrence with wide surgical margins remains the only surgically modifiable prognostic factor $[7,14]$.

What remains unknown, is what comprises an adequate surgical margin in high grade CS [8,15-17]. The width of a 'wide' margin has never been accurately defined and discrepancy exists in the practical definition of a wide margin [7-9,13,15,18].

The purpose of this current study was to investigate (1) the role of margins in local recurrence free survival (LRFS), and (2) the effect of LR on DSS in CS of the extremity and pelvis. Knowledge of this will help surgical planning, especially if the risk of LR can be evaluated, based on the expected margin of excision and the effect of LR on survival is known.

\section{Material and methods}

This retrospective study included 341 patients. Following institutional ethical review board approval, patients who had been diagnosed and surgically treated with a pelvic or extremity CS between 2003 and 2015 at the Royal Orthopedic Hospital NHS Foundation Trust, Birmingham, UK, were identified from a prospectively maintained database. All patients were diagnosed and treated at a single institution; those who were initially treated elsewhere and referred for the management of a recurrence were excluded. Details of the clinical data collected included the site (appendicular, extremity or pelvis), tumor size $(\mathrm{cm})$, type of operation (limb-salvage or amputation), gender, age, pathologic fracture and oncological outcomes, including local recurrence free survival (LRFS) and disease specific survival (DSS). A complete dataset was available for all patients included in the final analysis. A minimum two years' follow-up and complete histopathology records was required for all patients alive. Resection specimens were examined, by specialized bone sarcoma pathologists, for grade and involvement of margins. The highest grade seen on histology was the grade recorded, even when this higher grade comprised a small number of cells. Margins were measured on the histological slides in millimeters from the resection surface to the nearest viable tumor and classified as $<1 \mathrm{~mm}$ (including intralesional margin), $>1 \mathrm{~mm},>2 \mathrm{~mm},>3 \mathrm{~mm}$ and $>4 \mathrm{~mm}$. Three patients were excluded from the study as the closest surgical margin measurement was not recorded.

\section{Statistical analysis}

Descriptive statistics were used to display demographic data. The Kaplan-Meier method was used to determine LRFS and DSS. Survival rates were calculated from the date of diagnosis to the most recent follow-up, confirmation of local recurrence or death. Univariate analysis was performed by comparing groups with log-rank test with subsequent multivariate Cox proportional hazard analysis of significant variables to identify predictors of LRFS and DSS. A p value $<0.05$ was considered significant. Kruskal-Wallis test was used for statistical analysis means between the groups.

Subdistribution Hazard Ratio (SHR) of the role of LR on survival was calculated using competing risk analysis. Synchronous metastases (metastases developed before LR, at the time of LR or within 90 days after LR), and death due to other reason were considered as competing events in analyses of the role of LR on DSS. Receiver operating characteristics (ROC) curve analysis was used to determine a threshold value for margins predicting LR in higher grade tumors. Clinically significant incidence of LR was set in a pragmatic way to less than $10 \%$.

All other statistical analysis was completed using SPSS Statistics 21.0 (IBM, New York, USA) but competing risk analyses was performed using STATA 13 (Stata, College Station, Texas, USA).

\section{Results}

\section{Patient characteristics}

The final study population, comprised 341 patients, 58\% males and $42 \%$ females, with a mean age of 55.1 years (range $7-95$ ) and a mean follow-up of 44 months (range 0-162 months). 90 patients (26\%) had pelvic tumors, 210 (62\%) in extremities and $41(12 \%)$ in appendicular area (hand and foot). Histological grading of specimens was grade- 1 in 108 (32\%), grade-2 in 129 (38\%), grade-3 in 46 (14\%) and dedifferentiated in 58 (17\%) patients. Both the age and maximum size increased significantly from lower grade towards higher grade $(\mathrm{p}=<0.0001)$. Detailed patient characteristics are presented in Table 1.

\section{Predictors of local recurrence and local recurrence free survival}

Local recurrence developed in $78(23 \%)$ patients. The incidence of local recurrence (LR) was $12 \%(13 / 108)$ in grade-1 CS, 26\% (34/ $129)$ in grade- $2,37 \%(17 / 46)$ in grade- 3 and $24 \%(14 / 58)$ in dedifferentiated CS. Univariate analysis identified significant predictors

Table 1

Patient characteristics.

\begin{tabular}{|c|c|c|}
\hline Patient characteristics & Number & $\%$ \\
\hline Eligible patients & 341 & $100 \%$ \\
\hline \multicolumn{3}{|l|}{ Gender } \\
\hline Male & 197 & $58 \%$ \\
\hline Female & 144 & $42 \%$ \\
\hline \multicolumn{3}{|l|}{ Location } \\
\hline Pelvis & 90 & $26 \%$ \\
\hline Extremity & 210 & $62 \%$ \\
\hline Appendicular & 41 & $12 \%$ \\
\hline \multicolumn{3}{|l|}{ Grade } \\
\hline Grade 1 & 108 & $32 \%$ \\
\hline Pelvis (\% within grade) & 17 & $16 \%$ \\
\hline Extremity (\% within grade) & 73 & $68 \%$ \\
\hline Appendicular (\% within grade) & 18 & $16 \%$ \\
\hline Grade 2 & 129 & $38 \%$ \\
\hline Pelvis (\% within grade) & 43 & $33 \%$ \\
\hline Extremity (\% within grade) & 69 & $54 \%$ \\
\hline Appendicular (\% within grade) & 17 & $13 \%$ \\
\hline Grade 3 & 46 & $14 \%$ \\
\hline Pelvis (\% within grade) & 20 & $44 \%$ \\
\hline Extremity (\% within grade) & 22 & $48 \%$ \\
\hline Appendicular (\% within grade) & 4 & $9 \%$ \\
\hline Dedifferentiated & 58 & $17 \%$ \\
\hline Pelvis (\% within grade) & 10 & $17 \%$ \\
\hline Extremity (\% within grade) & 46 & $79 \%$ \\
\hline Appendicular (\% within grade) & 2 & $3 \%$ \\
\hline Pathologic fracture & 53 & $16 \%$ \\
\hline Conventional central & 300 & $88 \%$ \\
\hline Peripheral secondary to osteochondroma & 41 & $12 \%$ \\
\hline Multiple hereditary exostoses & 9 & $3 \%$ \\
\hline Ollier's disease & 8 & $2 \%$ \\
\hline Maffucci & 2 & $1 \%$ \\
\hline \multicolumn{3}{|l|}{ Surgical treatment } \\
\hline Curettage & 34 & $10 \%$ \\
\hline Resection & 238 & $70 \%$ \\
\hline Amputation & 69 & $20 \%$ \\
\hline Local recurrence & 78 & $23 \%$ \\
\hline \multicolumn{3}{|l|}{ Size (mean $\mathrm{cm}$ ) } \\
\hline Grade 1 & $8(1-25)$ & \\
\hline Grade 2 & $11(2-28)$ & \\
\hline Grade 3 & $13(2-28)$ & \\
\hline Dedifferentiated & $13(5-32)$ & \\
\hline \multicolumn{3}{|l|}{ Age (mean years, range) } \\
\hline Grade 1 & $46(7-85)$ & \\
\hline Grade 2 & $56(9-95)$ & \\
\hline Grade 3 & $62(23-86)$ & \\
\hline Dedifferentiated & $65(35-82)$ & \\
\hline
\end{tabular}


of LR as pelvic location ( $p=0.007)$, pathologic fracture $(\mathrm{p}=0.037)$, high histologic grade $(\mathrm{p}=<0.001)$ and margin $(\mathrm{p}=<0.001)$. Amputation when compared to limb salvage did not result in improved control of LR for all patients $(\mathrm{p}=0.152)$. When stratified by location, in the extremities, amputation resulted in improved control of LR $(\mathrm{p}=0.003)$ whereas in the pelvis there was no statistical significance $(\mathrm{p}=0.534)$. Results of multivariate analysis in predicting local recurrence are summarized in Table 2.

LR occurred in 61/238 (26\%) patients treated with surgical resection, $11 / 34$ (32\%) treated with intralesional curettage and 6/69 (9\%) treated with amputation $(\mathrm{p}=0.102) .44 / 78(65.4 \%)$ of those patients with LR developed metastases at some time. Among patients with LR, in grade-1 CS no patient developed metastases during the study period, in grade-2 CS 22/34 (64.7\%), in grade-3 CS $11 / 17$ (64.7\%) and in DD CS 11/14 (78.6\%) developed metastases. Grades of LRs, LR and metastases in different grades of CS are summarized in Table 3.

The predictive role of different margins in millimeters was investigated by stratifying tumors by grade and location. With 95\% sensitivity ROC curve analysis set the threshold level for margins up to $4 \mathrm{~mm}$ in grade-2, grade- 3 and DD tumors and $0.5 \mathrm{~mm}$ in grade-1 tumors. Kaplan-Meier analysis for LRFS illustrates the distribution demonstrates a significant difference achieved between groups with a surgical margin of $>4 \mathrm{~mm}$ ( $\mathrm{p}=0.000$ all high grades together, $\mathrm{p}=0.008$ for grade- 2 , $\mathrm{p}=0.041$ for grade- 3 , and $\mathrm{p}=0.043$ for DD CS). LRFSs for different grades of CS are summarized in Fig. 1 and the predictive role of margin in different grades and anatomic locations is summarized in appendix table 1 .

\section{Disease specific survival}

In general, in all CS grades, pathologic fracture $(\mathrm{p}=<0.001)$, central CS versus peripheral CS secondary to osteochondroma $(\mathrm{p}=<0.001)$, grade $(\mathrm{p}=<0.001), \mathrm{LR}(\mathrm{p}=<0.001)$, and age $(\mathrm{p}=<0.001)$

Table 2

Significant predictors of local recurrence identified by multivariate analysis.

\begin{tabular}{llll}
\hline & Hazard Ratio & $95 \%$ confidence interval & p-value \\
\hline Pelvic location & 4.70 & $1.11-19.95$ & 0.035 \\
Grade 1 CS & 0.34 & $0.19-0.62$ & 0.000 \\
Grade 2 CS & 2.17 & $1.25-3.78$ & 0.006 \\
Dedifferentiated CS & 2.78 & $1.54-5.01$ & 0.028 \\
Size in cm & 1.04 & $1.00-1.07$ & 0.028 \\
Margin in mm & 0.89 & $0.81-0.99$ & 0.028 \\
\hline
\end{tabular}

were significant factors after univariate analysis for DSS. After multivariate analysis, factors identified as significantly poor predictors for DSS were age (HR, 1.05; 95\% CI 1.04-1.06, $\mathrm{p}=<0.001$ ), grade-3 (HR, 2.25; 95\% CI, 1.35-3.76, $\mathrm{p}=0.002$ ) and DD CS (HR, 10.38; $95 \% \mathrm{CI}, 6.60-16.33, \mathrm{p}=<0.001$ ). The results of the role of $\mathrm{LR}$ in DSS, analyzed in a competing risk model, are summarized in Table 4 and Fig. 2. LR was a significant predictor of DSS for all grades of CS except dedifferentiated CS.

The mean time from LR to death from disease was 23 months (range 2-59 months) in grade-2 CS, 14 months (range 0-54 months) in grade- 3 CS and 5 months (0-17 months) in DD CS. The differences in means were statistically significant $(\mathrm{p}=0.003)$.

\section{Discussion}

Primary malignant cartilaginous tumors remain a challenge due to their varying histopathology, difficulty in pathological grading and clinical behavior. In predicting local control of the tumor, the current study attempts to give some answers to the one modifiable factor, surgical excision margin. We acknowledge that this study has limitations including the retrospective nature of its design. However, the accrual of patients was limited to twelve years in order to standardize the reporting of specimens and margins amongst our specialist histopathologists and also to minimize differences in surgical techniques and diagnostic approaches during this time period. Despite extensive experience in chondrosarcomas, histopathological grading remains difficult with the possibility of misdiagnosis.

Our results show surgical margin to have a significant impact on LRFS in all CS subtypes. The incidence of LR reduced with wider surgical margins. We have demonstrated that margins of less than $1 \mathrm{~mm}$ confer a significant risk of local recurrence, especially in grade $1 \mathrm{CS}$. In high grade CS a margin greater than $4 \mathrm{~mm}$ is required to reduce the risk of LR, and the risk of LR in higher grade tumors was significantly increased by a margin less than $4 \mathrm{~mm}$.

In grade-1 CS, intralesional curettage with or without adjuvant treatment has previously been favorably reported in extremity lesions, marginal resection has been advocated in central CS $[9-11,19,20]$. Our $12 \%$ LR rate in grade-1 CS is similar to previous reports which range from $0 \%$ to $18 \%$ [9-11,21,22]. LR in grade- 1 CS had no impact on DSS as none of the patients with grade- 1 tumors died as a result of metastases from their recurrent CS. The 100\% 10 -year DSS in grade-1 CS patients is superior to previous literature (range $82 \%-95 \%$ ), which we attribute to variance in histological grading between treating centers and potentially some grade- 2 CS inadvertently being included in grade- 1 groups in previous studies $[8,23]$. The rationale for achieving wide margins

Table 3

The number of patients with or without local recurrence and/or metastases.

\begin{tabular}{|c|c|c|c|c|}
\hline & Grade $1 \mathrm{CS}$ & Grade 2 CS & Grade 3 CS & DD CS \\
\hline No LR and no metastases & $95(88.0 \%)$ & $83(64.3 \%)$ & $20(43.5 \%)$ & $20(34.5 \%)$ \\
\hline LR without metastases & $13(12.0 \%)$ & $12(9.3 \%)$ & $6(13.0 \%)$ & $3(5.2 \%)$ \\
\hline LR with metastases prior to LR or synchronous within 90 days & 0 & $15(11.6 \%)$ & $9(19.6 \%)$ & $9(15.5 \%)$ \\
\hline LR with metastases after 90 days & 0 & $7(5.4 \%)$ & $2(4.3 \%)$ & $2(3.4 \%)$ \\
\hline Metastases without LR & 0 & $12(9.3 \%)$ & $9(19.6 \%)$ & $23(39.7 \%)$ \\
\hline \multicolumn{5}{|l|}{ Grade of LR } \\
\hline Not assessed & $6(46 \%)$ & $6(18 \%)$ & $8(47 \%)$ & $4(29 \%)$ \\
\hline Grade1 & $2(15 \%)$ & $4(12 \%)$ & - & - \\
\hline Grade 2 & $4(31 \%)$ & $19(56 \%)$ & $5(29 \%)$ & - \\
\hline Grade 3 & - & $3(9 \%)$ & $4(24 \%)$ & - \\
\hline DD & $1(8 \%)$ & $2(6 \%)$ & - & $10(71 \%)$ \\
\hline
\end{tabular}

$\mathrm{LR}=$ local recurrence.

$\mathrm{CS}=$ chondrosarcoma.

$\mathrm{DD}=$ dedifferentiated. 

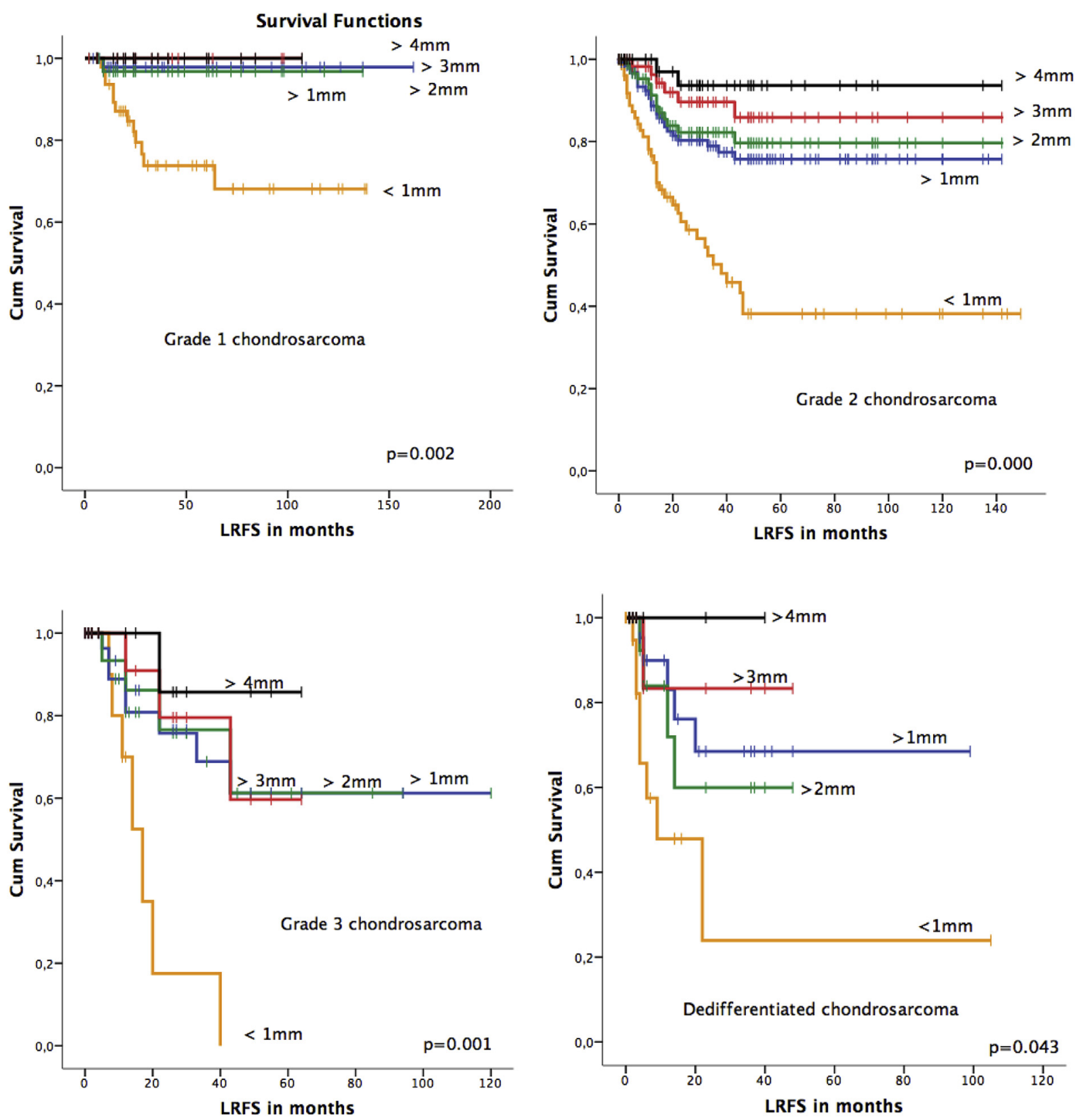

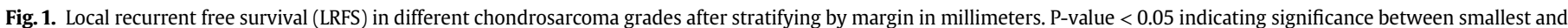
the other marginal options.

in grade-1 CS, is therefore lacking. However, as reported in our previously published article, pre-operatively identifying true grade- 1 CS remains a challenge; approximately $50 \%$ of grade- 1 biopsies were upgraded after surgical excision [24]. Therefore, the remaining challenge in suspected low-grade CS is to accurately discriminate between grade- 1 and grade- 2 , because of the significantly worse clinical behavior in high grade CS. Although an intralesional margin in true grade- 1 CS is acceptable, it remains critical to adhere to oncological orthopedic principles, in order to not compromise any subsequent surgery if a lesion is subsequently found to be higher grade.

In grade- 2 and -3 CS, a wide surgical margin remains the most critical factor associated with local control, because each millimetric increase in margin reduced LR incidence. However, the role of LR on DSS is more complicated as high grade CS may develop metastases without LR. To predict the role of LR on survival we used competing risk analysis, which may also add information from intermediate events that occur during follow-up such as metastases prior to LR or synchronous metastases occurring within three months of LR or death from other causes, (our competing events). Our competing risk analysis model showed that LR was strongly predictive of DSS in grade- 2 and grade- 3 CS when synchronous metastases or death for other reason were the competing risks. Wherever possible, wide margins should be sought to reduce the risk of LR and its effect on metastases.

In grade- 2 and grade- 3 CS, metastases developed greater than 3 months following LR in $21.2 \%$ and $10.2 \%$ of patients respectively. However, in DD CS, metastasis occurred often prior to LR or in the absence of LR. This reflects the aggressive nature of the DD variant of CS, and is manifest as a high incidence of systemic relapse and high rates of mortality. Unlike grade-2 and grade-3 CS, the role of LR in DSS for DD CS when studied with competing risk analysis was 
Table 4

Role of local recurrence in disease specific survival analyzed in a competing risk model.

\begin{tabular}{|c|c|c|c|}
\hline & Subdistribution Hazard Ratio & 95\% confidence interval & p-value \\
\hline All grades together & 7.33 & $3.78-14.21$ & 0.000 \\
\hline Grade 1 CS & 1 & - & - \\
\hline Grade 2 CS & 16.65 & $3.67-74.11$ & 0.000 \\
\hline Grade 3 CS & 7.36 & $1.56-34.78$ & 0.012 \\
\hline Dedifferentiated CS & 2.45 & $0.96-6.24$ & 0.060 \\
\hline
\end{tabular}

not statistically significant. This may reflect the relatively small number of patients with DD CS included in this study.

As stated in previous reports, surgical margin is not an independent predictor of DSS in all grades of CS [6,7]. However, margin is a significant predictor of LRFS in all grades of CS. Grade- 1 CS had a very low likelihood of LR, and therefore treatment decisions that optimize functional outcomes are justified. This applies only to true grade 1 tumors and highlights the importance of accurate histological grading. In grade- 2 and grade- 3 CS, the margin achieved at resection had an effect on both LRFS and DSS; grade-2 and grade-3 CS may be considered a surgical disease in that all attempts should be made to reduce the risk of LR because of the negative effect of LR on DSS. In DD CS, margins have a significant role in LRFS, the effect of margin on LR and DSS did not show statistical significance. Amputation resulted in a reduction in LR when compared to limb salvage in extremity tumors but not in

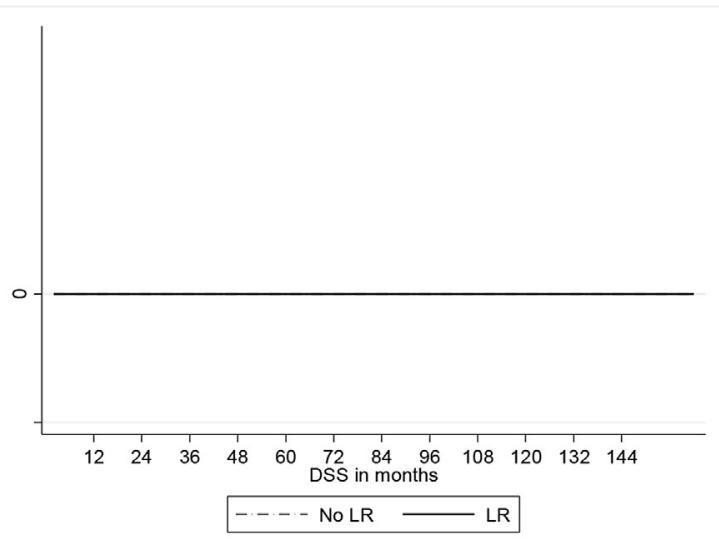

Grade 1 chondrosarcoma

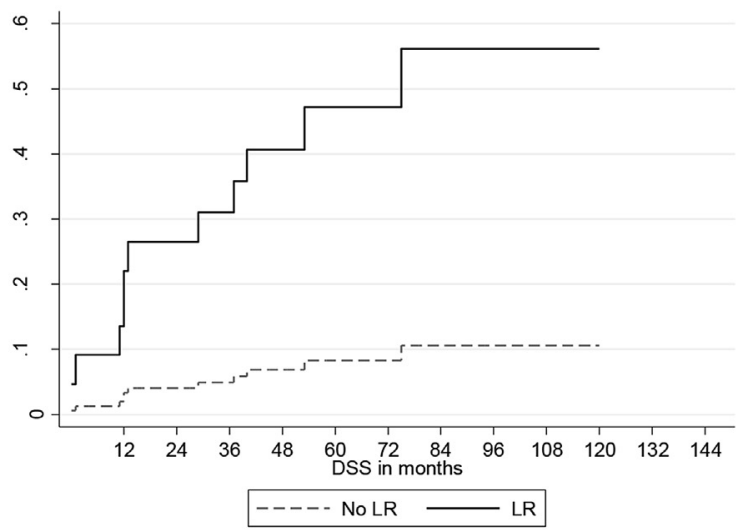

Grade 3 chondrosarcoma, $\mathrm{p}=0.012$ pelvic tumors. In the pelvis, this is likely to reflect the larger size tumors in the group of patients treated by amputation. Peripheral CS had a better DSS than central CS which may reflect the lower grade commonly seen in peripheral CS. However, as we have shown in our previously published article, one of the greatest challenges in the management of CS is to accurately assess the grade of the tumor prior to surgical intervention [24]. As biopsy has been shown to be often unreliable, the decision must be based on a multidisciplinary approach.

Age as a predictor of survival in CS remains an area of debate. Stihsen et al., recently demonstrated that age was a strong predictor for survival in CS [25]. By contrast, we have demonstrated that age alone is not a significant factor for survival but does have a significant effect on survival when considered in association with the grade of the tumor. The effect of age on overall survival is most profound for grade 2 CS. This of course, reflects the age at diagnosis

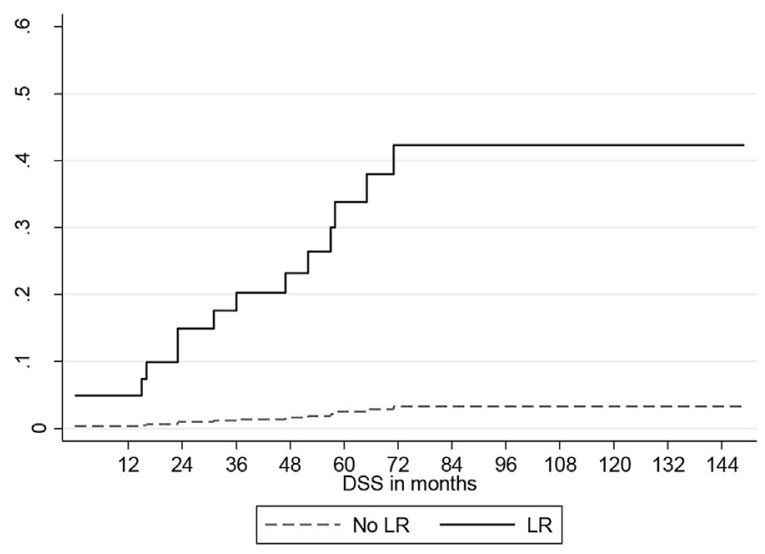

Grade 2 chondrosarcoma, $p=0.000$

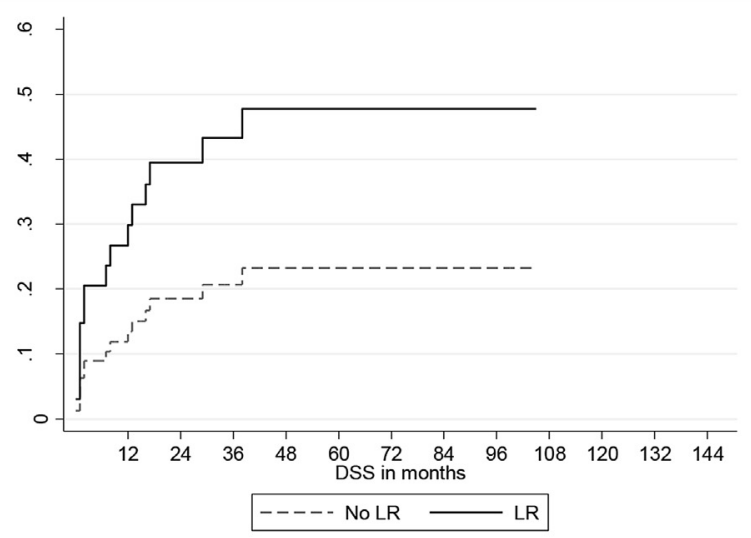

Dedifferentiated chondrosarcoma, $\mathrm{p}=0.060$

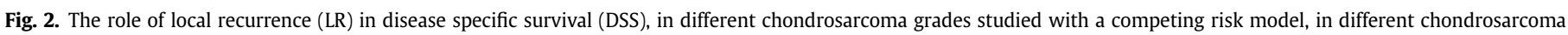
grades. P-value $<0.05$ indicating significance. 
of the differing grades of tumors with higher grade tumors being more common in more elderly patients.

Even though surgical margin and DSS did not demonstrate a direct association, the LRFS in both high grade CS and grade-1 CS were dependent on the surgical margin; wider margins improved LRFS in all tumor grades. Previous studies have only defined a sufficient margin for resection of CS as 'wide margin' [8,9,26,27]. A wide margin is difficult to quantify and most surgeons accept that negative margins, wide margins and acceptable margins are not necessarily the same thing. We have demonstrated that when qualitative measures of margin are replaced with quantitative metric measures, the effect of margin on LRFS and DSS becomes more apparent. As the rate of LR decreases with wider margins, the balance between the morbidity associated with more aggressive resection and the risk of LR must be discussed on a case by case basis, particularly in young patients in whom more conservative treatments for lower grade tumors must be offset by the reduced risk of LR conferred by wider resections.

In conclusion, for local tumor control, the primary goal is to achieve a sufficient surgical margin to prevent local recurrence. However, the term 'wide margin' is unfit for this purpose as this varies between grades; narrow margins are acceptable in truly grade- 1 tumors, but as biopsy has been shown to be unreliable in predicting the final grade in low grade CS, it is our opinion that surgeons should aim to achieve a 4-mm margin in all grades to reduce the risk of LR and its effect on DSS. Surgical margin is crucial as local recurrence has a significant role in the disease specific survival shown statistically in grade- 2 and grade- 3 CS, the most common grades of chondrosarcoma.

\section{Source of funding}

The study was funded by Pirkanmaa Cancer Society.

\section{Conflicts of interest statement}

All authors declare no conflict of interest.

\section{Appendix}

Table 1

One- and five-year local recurrence free survival (LRFS) rates stratified by margin in millimeters, grade and location.

\begin{tabular}{ccc}
\hline & 1 -year LRFS & 5-years LRFS \\
\hline Grade 1 CS & & \\
$<1 \mathrm{~mm}$ all sites & $94.8 \%$ & $73.7 \%$ \\
$>1 \mathrm{~mm}$ all sites & $97.7 \%$ & $97.7 \%$ \\
$>2 \mathrm{~mm}$ all sites & $96.8 \%$ & $96.8 \%$ \\
$>3 \mathrm{~mm}$ all sites & $100 \%$ & $100 \%$ \\
$>4 \mathrm{~mm}$ all sites & $100 \%$ & $100 \%$ \\
$<1 \mathrm{~mm}$ pelvis & $92.9 \%$ & $62.7 \%$ \\
$>1 \mathrm{~mm}$ pelvis & $100 \%$ & $100 \%$ \\
$>2 \mathrm{~mm}$ pelvis & $100 \%$ & $100 \%$ \\
$>3 \mathrm{~mm}$ pelvis & $100 \%$ & $100 \%$ \\
$>4 \mathrm{~mm}$ pelvis & $100 \%$ & $100 \%$ \\
$<1 \mathrm{~mm}$ extremities & $97.2 \%$ & $74.0 \%$ \\
$>1 \mathrm{~mm}$ extremities & $97.0 \%$ & $97.0 \%$ \\
$>2 \mathrm{~mm}$ extremities & $96.2 \%$ & $96.2 \%$ \\
$>3 \mathrm{~mm}$ extremities & $100 \%$ & $100 \%$ \\
$>4 \mathrm{~mm}$ extremities & $100 \%$ & $100 \%$ \\
Grade 2 CS & & \\
$<1 \mathrm{~mm}$ all sites & $86.1 \%$ & $53.2 \%$ \\
$>1 \mathrm{~mm}$ all sites & $93.5 \%$ & $85.9 \%$ \\
$>2 \mathrm{~mm}$ all sites & $94.7 \%$ & $86.3 \%$
\end{tabular}

Table 1 (continued)

\begin{tabular}{|c|c|c|}
\hline & 1-year LRFS & 5-years LRFS \\
\hline$>3 \mathrm{~mm}$ all sites & $100 \%$ & $93.8 \%$ \\
\hline$>4 \mathrm{~mm}$ all sites & $100 \%$ & $92.6 \%$ \\
\hline$<1 \mathrm{~mm}$ pelvis & $81.8 \%$ & $47.0 \%$ \\
\hline$>1 \mathrm{~mm}$ pelvis & $88.9 \%$ & $74.1 \%$ \\
\hline$>2 \mathrm{~mm}$ pelvis & $93.3 \%$ & $74.7 \%$ \\
\hline$>3 \mathrm{~mm}$ pelvis & $100 \%$ & $60.0 \%$ \\
\hline$>4 \mathrm{~mm}$ pelvis & $100 \%$ & $33.3 \%$ \\
\hline$<1 \mathrm{~mm}$ extremities & $90.0 \%$ & $53.8 \%$ \\
\hline$>1 \mathrm{~mm}$ extremities & $94.1 \%$ & $87.3 \%$ \\
\hline$>2 \mathrm{~mm}$ extremities & $93.7 \%$ & $86.4 \%$ \\
\hline$>3 \mathrm{~mm}$ extremities & $100 \%$ & $100 \%$ \\
\hline$>4 \mathrm{~mm}$ extremities & $100 \%$ & $100 \%$ \\
\hline \multicolumn{3}{|l|}{ Grade 3 CS } \\
\hline$<1 \mathrm{~mm}$ all sites & $66.7 \%$ & $0 \%$ \\
\hline$>1 \mathrm{~mm}$ all sites & $80.8 \%$ & $61.2 \%$ \\
\hline$>2 \mathrm{~mm}$ all sites & $86.2 \%$ & $61.3 \%$ \\
\hline$>3 \mathrm{~mm}$ all sites & $90.9 \%$ & $59.7 \%$ \\
\hline$>4 \mathrm{~mm}$ all sites & $100 \%$ & $85.7 \%$ \\
\hline$<1 \mathrm{~mm}$ pelvis & $80.0 \%$ & $0 \%$ \\
\hline$>1 \mathrm{~mm}$ pelvis & $68.4 \%$ & $34.2 \%$ \\
\hline$>2 \mathrm{~mm}$ pelvis & $71.4 \%$ & $35.7 \%$ \\
\hline$>3 \mathrm{~mm}$ pelvis & $71.4 \%$ & $28.6 \%$ \\
\hline$>4 \mathrm{~mm}$ pelvis & $100 \%$ & $100 \%$ \\
\hline$<1 \mathrm{~mm}$ extremities & $50.0 \%$ & $0 \%$ \\
\hline$>1 \mathrm{~mm}$ extremities & $90.0 \%$ & $80.0 \%$ \\
\hline$>2 \mathrm{~mm}$ extremities & $100 \%$ & $80 \%$ \\
\hline$>3 \mathrm{~mm}$ extremities & $80 \%$ & $80 \%$ \\
\hline$>4 \mathrm{~mm}$ extremities & $100 \%$ & $80 \%$ \\
\hline \multicolumn{3}{|l|}{ Dedifferentiated CS } \\
\hline$<1 \mathrm{~mm}$ all sites & $48.5 \%$ & $24.2 \%$ \\
\hline$>1 \mathrm{~mm}$ all sites & $83.0 \%$ & $68.5 \%$ \\
\hline$>2 \mathrm{~mm}$ all sites & $83.9 \%$ & $59.9 \%$ \\
\hline$>3 \mathrm{~mm}$ all sites & $83.3 \%$ & $83.3 \%$ \\
\hline$>4 \mathrm{~mm}$ all sites & $100 \%$ & $100 \%$ \\
\hline$<1 \mathrm{~mm}$ pelvis & $100 \%$ & $100 \%$ \\
\hline$>1 \mathrm{~mm}$ pelvis & $75.0 \%$ & $50 \%$ \\
\hline$>2 \mathrm{~mm}$ pelvis & $100 \%$ & $50 \%$ \\
\hline$>3 \mathrm{~mm}$ pelvis & $100 \%$ & $100 \%$ \\
\hline$>4 \mathrm{~mm}$ pelvis & $100 \%$ & $100 \%$ \\
\hline$<1 \mathrm{~mm}$ extremities & $45.6 \%$ & $22.8 \%$ \\
\hline$>1 \mathrm{~mm}$ extremities & $75.4 \%$ & $75.4 \%$ \\
\hline$>2 \mathrm{~mm}$ extremities & $78.8 \%$ & $59.1 \%$ \\
\hline$>3 \mathrm{~mm}$ extremities & $75.0 \%$ & $75.0 \%$ \\
\hline$>4 \mathrm{~mm}$ extremities & $100 \%$ & $100 \%$ \\
\hline
\end{tabular}

$\mathrm{CS}=$ chondrosarcoma

\section{References}

[1] Evans HL, Ayala AG, Romsdahl MM. Prognostic factors in chondrosarcoma of bone: a clinicopathologic analysis with emphasis on histologic grading. Cancer 1977;40(2):818-31.

[2] Gelderblom H, Hogendoorn PC, Dijkstra SD, van Rijswijk CS, Krol AD, Taminiau AH, et al. The clinical approach towards chondrosarcoma. Oncologist 2008;13(3):320-9. Epub 2008/04/02.

[3] Bertoni O, Bacchini P, Hogendoorn P. Chondrosarcoma. In: Fletcher CDM, Unni KK, Mertens F, editors. health organization classification of tumours pathology and genetics of tumours of soft tissue and bone. Lyon France: IARC Press; 2002. p. 247-51.

[4] Fletcher CDM. In: Fletcher CDM, Bridge JA, Hogendoorn P, Mertens F, editors. WHO classification of tumours of soft tissue and bone. fourth ed. Lyon: IARC; 2013.

[5] Milchgrub S, PCW H. In: Fletcher C, Unni K, Mertens F, editors. Dedifferentiated chondrosarcoma. Lyon, France: IARC Press; 2002.

[6] Lee FY, Mankin HJ, Fondren G, Gebhardt MC, Springfield DS, Rosenberg AE, et al. Chondrosarcoma of bone: an assessment of outcome. J Bone Joint Surg Am 1999:81(3):326-38.

[7] Fiorenza F, Abudu A, Grimer RJ, Carter SR, Tillman RM, Ayuob K, et al. Risk factors for survival and local control in chondrosarcoma of bone. J Bone Joint Surg Br 2002 Jan;84(1):93-9.

[8] Angelini A, Guerra G, Mavrogenis AF, Pala E, Picci P, Ruggieri P. Clinical outcome of central conventional chondrosarcoma. J Surg Oncol 2012;106(8): 929-37.

[9] Andreou D, Gilg MM, Gosheger G, Werner M, Hardes J, Pink D, et al. Metastatic potential of grade I chondrosarcoma of bone: results of a multi-institutional study. Ann Surg Oncol 2016;23(1):120-5. 
[10] Campanacci DA, Scoccianti G, Franchi A, Roselli G, Beltrami G, Ippolito M, et al. Surgical treatment of central grade 1 chondrosarcoma of the appendicular skeleton. J Orthop Traumatol 2013;14(2):101-7.

[11] Verdegaal SH, Brouwers HF, van Zwet EW, Hogendoorn PC, Taminiau AH. Low-grade chondrosarcoma of long bones treated with intralesional curettage followed by application of phenol, ethanol, and bone-grafting. J Bone Joint Surg Am 2012;94(13):1201-7.

[12] Donati D, El Ghoneimy A, Bertoni F, Di Bella C, Mercuri M. Surgical treatment and outcome of conventional pelvic chondrosarcoma. J Bone Joint Surg $\mathrm{Br}$ 2005;87(11):1527-30.

[13] Nota SP, Braun Y, Schwab JH, van Dijk CN, Bramer JA. The identification of prognostic factors and survival statistics of conventional central chondrosarcoma. Sarcoma 2015:623746.

[14] Schwab JH, Wenger D, Unni K, Sim FH. Does local recurrence impact survival in low-grade chondrosarcoma of the long bones? Clin Orthop Relat Res 2007; 462:175-80.

[15] Mavrogenis AF, Angelini A, Drago G, Merlino B, Ruggieri P. Survival analysis of patients with chondrosarcomas of the pelvis. J Surg Oncol 2013;108(1):19-27.

[16] Aarons C, Potter BK, Adams SC, Pitcher Jr JD, Temple HT. Extended intralesional treatment versus resection of low-grade chondrosarcomas. Clin Orthop Relat Res 2009;467(8):2105-11.

[17] Cho WH, Song WS, Jeon DG, Kong CB, Koh JS, Kim JI, et al. Oncologic impact of the curettage of grade 2 central chondrosarcoma of the extremity. Ann Surg Oncol 2011;18(13):3755-61.

[18] Albergo JI, Gaston CL, Jeys LM, Khajuria A, Carter SR, Tillman RM, et al. Management and prognostic significance of pathological fractures through chondrosarcoma of the femur. Int Orthop 2015;39(5):943-6.
[19] Hanna SA, Whittingham-Jones P, Sewell MD, Pollock RC, Skinner JA, Saiffudin A, et al. Outcome of intralesional curettage for low-grade chondrosarcoma of long bones. Eur J Surg Oncol 2009;35(12):1343-7.

[20] Donati D, Colangeli S, Colangeli M, Di Bella C, Bertoni F. Surgical treatment of grade I central chondrosarcoma. Clin Orthop Relat Res 2010;468(2):581-9.

[21] Leerapun T, Hugate RR, Inwards CY, Scully SP, Sim FH. Surgical management of conventional grade I chondrosarcoma of long bones. Clin Orthop Relat Res 2007;463:166-72.

[22] Funovics PT, Panotopoulos J, Sabeti-Aschraf M, Abdolvahab F, Funovics JM Lang S, et al. Low-grade chondrosarcoma of bone: experiences from the vienna bone and soft tissue tumour registry. Int Orthop 2011;35(7):1049-56.

[23] Ozaki T, Lindner N, Hillmann A, Rodl R, Blasius S, Winkelmann W. Influence of intralesional surgery on treatment outcome of chondrosarcoma. Cancer 1996;77(7):1292-7.

[24] Laitinen MK, Stevenson JD, Parry MC, Sumathi V, Grimer RJ, Jeys LM. The role of grade in local recurrence and the disease-specific survival in chondrosarcoma. Bone Joint J 2018;100-B(5):662-6.

[25] Stihsen C, Panotopoulos J, Puchner SE, Sevelda F, Kaider A, Windhager R, et al. The outcome of the surgical treatment of pelvic chondrosarcomas: competing risk analysis of 58 tumours from a single centre. Bone Joint J 2017;99(5):686-96.

[26] Kim HS, Bindiganavile SS, Han I. Oncologic outcome after local recurrence of chondrosarcoma: analysis of prognostic factors. J Surg Oncol 2015;111(8): 957-61.

27] Hickey M, Farrokhyar F, Deheshi B, Turcotte R, Ghert M. A systematic review and meta-analysis of intralesional versus wide resection for intramedullary grade 1 chondrosarcoma of the extremities. Ann Surg Oncol 2011;18(6):1705-9. 